\title{
Colorectal Cancer Screening: Impact of COVID-19 Pandemic and Possible Consequences
}

\author{
Isabelle Harber, Dania Zeidan and Muhammad N. Aslam *D \\ Department of Pathology, University of Michigan Medical School, Ann Arbor, MI 48109, USA; \\ isharber@umich.edu (I.H.); zeidania@umich.edu (D.Z.) \\ * Correspondence: mnaslam@med.umich.edu; Tel.: +1-(734)-936-1897
}

Citation: Harber, I.; Zeidan, D.; Aslam, M.N. Colorectal Cancer Screening: Impact of COVID-19 Pandemic and Possible Consequences. Life 2021, 11, 1297. https://doi.org/10.3390/ life11121297

Academic Editors: Anca Oana Docea and Daniela Calina

Received: 27 October 2021

Accepted: 24 November 2021

Published: 26 November 2021

Publisher's Note: MDPI stays neutral with regard to jurisdictional claims in published maps and institutional affiliations.

Copyright: (c) 2021 by the authors. Licensee MDPI, Basel, Switzerland. This article is an open access article distributed under the terms and conditions of the Creative Commons Attribution (CC BY) license (https:// creativecommons.org/licenses/by/ $4.0 /)$.

\begin{abstract}
Colonoscopy procedure has been the key screening method to detect colorectal cancer (CRC). As a fatal disease, CRC needs early detection. The COVID-19 pandemic caused screening tests (colonoscopy) to be halted and delayed. As a result, there could be dire consequences such as later-stage or missed diagnosis or greater mortality. This report will analyze scientific literature pertaining to interrupted CRC screenings due to COVID-19 while drawing historical parallels from the 1918 flu pandemic. We conducted literature searches in the PubMed database as well as in Google Scholar. One of the main lessons learned from the $1918 \mathrm{flu}$ pandemic was to employ social distancing to stop the spread of the virus. So, the global response at the start and peak of the COVID-19 pandemic was decreased hospital visits for any non-emergency cases. That led to a halt and delays in cancer (including CRC) screenings. The Medical community predicted this lag will cause more CRC cases and deaths in the future. However, reorganizing and changing screening method strategies were helpful during the ongoing pandemic. In conclusion, COVID-19 greatly affected CRC screening, including how we view the future of CRC screening. We can learn from this prospect to better prepare for future pandemics or other public health crises.
\end{abstract}

Keywords: colorectal cancer; CRC screening; COVID-19; Spanish flu; pandemic

\section{Introduction and Background}

In 1918, the world faced a public health crisis known as the 1918 influenza pandemic or also known as the Spanish flu. This H1N1 influenza virus killed an estimated 50 million people worldwide [1-3]. Now, about 103 years later, the world is facing yet another devastating public health crisis-COVID-19, a respiratory disease caused by the novel coronavirus SARS-CoV-2 [4]. According to the John Hopkins University COVID-19 tracker, as of 25 November 2021, COVID-19 infection has been diagnosed in over 259 million people and has killed around 5.2 million people worldwide since the beginning of the pandemic. The United States of America (USA) alone is one of the worst-affected countries, with over 48 million cases and 775,628 deaths due to COVID-19 so far [5]. According to the CDC data, despite all of the scientific advancements, COVID-19 cases and casualties in the USA have surpassed the 1918 influenza pandemic death toll (of 675,000) [2]. We are still in the midst of the COVID-19 pandemic as COVID-19 infections in the United States, and several parts of the world (in hotspots zones) are rising even after the launch of successful COVID-19 vaccination programs. Table 1 breaks down the comparison of two pandemics, cases caused by 1918 Flu and COVID-19 and fatalities due to these infections.

The COVID-19 infectious disease poses a serious threat to people with underlying chronic conditions, including cancer. One of the most serious threats and concomitant manifestations of the surge in COVID-19 cases was a sharp decline in the screening of different types of cancers, i.e., breast, cervix, lung, and colon/rectum, at the early stages of the COVID-19 pandemic [6,7]. In addition to a decrease in the screening procedures, COVID-19 impacted colorectal cancer (CRC) care during the pandemic. This effect was due 
to the inadequacy of health care systems, lack of preparedness, availability of resources, and increased burden of COVID-19 cases [8]. The focus in this literature review will be on the effect of the COVID-19 pandemic on CRC screening.

Table 1. Number of Cases and Deaths of 1918 Flu and COVID-19 Pandemics.

\begin{tabular}{ccccc}
\hline \multirow{2}{*}{ Pandemics } & \multicolumn{2}{c}{ Total Cases } & \multicolumn{2}{c}{ Total Deaths } \\
\cline { 2 - 5 } & World & USA & World & USA \\
\hline 1918 Flu $^{\text {a }}$ & $500,000,000$ & $29,400,000$ & $50,000,000$ & 675,000 \\
COVID-19 $^{\text {b }}$ & $259,819,859$ & $48,107,102$ & $5,180,137$ & 775,628 \\
\hline
\end{tabular}

a Source: https://www.cdc.gov/flu/pandemic-resources/1918-pandemic-h1n1.html (accessed on 21 November 2021). ${ }^{\mathbf{b}}$ Source: https:/ / coronavirus.jhu.edu/map.html. (As of 25 November 2021).

CRC is the third most frequently diagnosed cancer type in the USA [9]. Risk factors of CRC include older age, obesity, alcohol use, tobacco use, family history of CRC, hereditary genetic mutations, and presence of inflammatory bowel disease (the duration, extent, age at onset, and the relation of primary sclerosing cholangitis of the IBD further affect CRC risk) [10]. CRC arises from the formation of polyps, unusually large growths in the colon or rectum. It is possible for polyps to progress to tumors, and expression profiles of proteins like cytokeratins and mucins can help determine prognosis and targeted therapy for specific types of colonic cancer [11]. There are many different types of screening tests that can detect these colonic polyps. These screening tests are important preventive measures for early CRC detection. Early detection of CRC (by way of screening tests) is of vital importance in preventing CRC and catching it before it progresses to a more severe stage. In fact, because regular screening has increased so much within the past 20-30 years, the death rate of CRC has been decreasing [9]. And of course, the decrease in death rate is also because of improved treatment options and targeted therapies [12]. Similarly, dietary and chemopreventive measures also play a role in decreasing the overall incidence of CRC $[13,14]$.

Currently used screening methods include invasive tests such as colonoscopy and flexible sigmoidoscopy; or minimally invasive tests like colon capsule endoscopy (CCE); and noninvasive tests-the guaiac-based fecal occult blood test (FOBT), fecal immunochemical test (FIT), FIT-DNA test, and computed tomography colonography (CTC) [15]. Colonoscopy is arguably the most effective (gold-standard) screening method currently available since the invention of fiber-optic endoscopes in the late 1960s [16,17]. It gives physicians the ability to examine the entire colon and rectum of a patient and remove polyps at the same time [17]. The first rigid sigmoidoscope was available in 1805 (before the start of 1918 pandemic) to examine the last part of the colon for screening purposes [18]. Sigmoidoscope has also evolved and has been modernized $[19,20]$. Flexible sigmoidoscopy proceeds by the same mechanism as colonoscopy but does not examine the entire colon $[19,20]$, while CCE is a relatively new method in which a pill with a camera takes pictures of the gastrointestinal tract when swallowed [21,22]. The noninvasive tests listed above are all stool tests except for CTC, testing patients' stool samples to detect occult blood, or DNA [15]. Table 2 below further highlights the differences between the types of screening tests [15] and their pertinence during the COVID-19 pandemic.

At the beginning of the COVID-19 pandemic, there was a complete halt in CRC screenings due to efforts to minimize person-to-person contact and to conserve hospital and medical resources for those exposed to COVID-19 [6]. Unfortunately, the postponement of these screening tests for patients has had and will continue to have dire consequences, including more cases of CRC - potentially more severe ones-and additional CRC deaths that would have been prevented otherwise. With delayed or altogether missed screenings comes the potential for missed opportunities to detect polyps, diagnose CRC, and get more treatment for patients diagnosed. 
Table 2. Most Common Types of Colorectal Cancer (CRC) Screening Tests.

\begin{tabular}{|c|c|c|c|c|}
\hline $\begin{array}{l}\text { Type of Screening } \\
\text { Method }\end{array}$ & Invasiveness & Method & $\begin{array}{l}\text { Location to Conduct } \\
\text { (Hospital or Home) }\end{array}$ & Frequency \\
\hline Colonoscopy & Invasive & $\begin{array}{l}\text { Colonoscope is used to } \\
\text { examine colon and rectum; } \\
\text { image transmitted }\end{array}$ & $\begin{array}{l}\text { Hospital (needed an } \\
\text { expert GI physician) }\end{array}$ & $\begin{array}{c}\text { Once every } 10 \text { years (if } \\
\text { normal) }\end{array}$ \\
\hline Flexible Sigmoidoscopy & Invasive & $\begin{array}{l}\text { Same procedure as a } \\
\text { colonoscopy except that only } \\
\text { last one third of the colon is } \\
\text { examined (instead of both } \\
\text { the colon and rectum) }\end{array}$ & $\begin{array}{l}\text { Hospital (needed an } \\
\text { expert GI physician) }\end{array}$ & Once every 5 years \\
\hline $\begin{array}{l}\text { Colon Capsule } \\
\text { Endoscopy }\end{array}$ & Slightly invasive & $\begin{array}{l}\text { Unlike colonoscopy, orally } \\
\text { ingested pill camera is used } \\
\text { to transmit images }\end{array}$ & $\begin{array}{c}\text { Home (needed GI } \\
\text { physician to evaluate } \\
\text { images) }\end{array}$ & Not established yet \\
\hline $\begin{array}{l}\text { Guaiac-Based Fecal } \\
\text { Occult Blood Test }\end{array}$ & Non-invasive & $\begin{array}{l}\text { Stool test; detects blood in } \\
\text { stool using the chemical } \\
\text { guaiac }\end{array}$ & Home & Once every year \\
\hline $\begin{array}{c}\text { Fecal Immunochemical } \\
\text { Test (FIT) }\end{array}$ & Non-invasive & $\begin{array}{l}\text { Stool test; detects blood in } \\
\text { stool using antibodies }\end{array}$ & Home & Once every year \\
\hline FIT-DNA Test & Non-invasive & $\begin{array}{c}\text { Stool test; detects altered } \\
\text { DNA }\end{array}$ & Home & Once every 1 or 3 years \\
\hline CT Colonography & Non-invasive & $\begin{array}{l}\text { Technology like X-rays used } \\
\text { to capture complete images } \\
\text { of the colon }\end{array}$ & $\begin{array}{l}\text { Hospital (needed } \\
\text { expert to read) }\end{array}$ & Once every 5 years \\
\hline
\end{tabular}

There are no clear data in the existing literature showing the effects of the $1918 \mathrm{flu}$ pandemic on the incidence or mortality of colorectal cancer during or after the pandemic. Myrskylä et al. published a study in 2013, explaining the early life exposure to the 1918 influenza pandemic and cause of death later in life (old age). The study showed that early age influenza exposure increased old-age mortality through noncancer causes (including respiratory and cardiovascular diseases) [3]. Furthermore, Wingo et al. published a paper in 2003, presenting long-term trends in cancer mortality in the USA from 1930 to 1998. It was found that the mortality rate of colon cancer declined over seven decades, going from $15.9 \%$ in the 1930 s to $10.4 \%$ in the 1990 s, with the highest mortality of $16.9 \%$ in the 1940s [23].

Siegel et al. documented long-term trends in CRC incidence from 1975-2010 and mortality rate from 1930-2010 in the USA. They concluded that CRC was the most common cause of cancer death in the USA in the late 1940s and early 1950s and after that, the mortality rate began to fall in the early 1950s [24]. In another publication, Siegel et al. presented that the age-specific risk of a CRC diagnosis fell for consecutive generations in the first half of the twentieth century but increased back to the level of those born in the late 1800s for current birth cohorts [25]. By reviewing this literature, it is difficult to make any connection to the after-effects of the 1918 flu pandemic on the incidence or mortality of CRC. What impact COVID-19 will have on the incidence and mortality of CRC is ultimately unclear, but we can predict from the suggestive tell-tale signs along with prediction models and population data.

There have been several papers published since the COVID-19 pandemic began about COVID-19-related CRC-screening delays, along with how these delays could impact future CRC incidence, mortality, and screening methods. Many of these papers are highly quantitative and some contain models relating to the prediction of future CRC statistics, including the number of CRC screening tests done pre-pandemic versus in the pandemic itself and after. This review will aim to highlight the important statistics and information regarding delayed CRC screenings, providing people in the public health field a holistic understanding of COVID-19's impact on CRC screening, including those who may not 
necessarily have a wider knowledge of CRC. This review will also place the context of the pandemic's impact on CRC concerning how CRC was affected by pandemics and epidemics of the past, such as the 1918 influenza pandemic. This comparison makes it more distinct from other literature reviews.

\section{Materials and Methods}

In order to conduct the literature review, we first described our topic and created an outline to better specify the types of sources and the content of information we would cite and reference in the literature review. We conducted searches in PubMed and Google Scholar databases using search terms including, but not limited to, "colorectal cancer COVID-19," "colon cancer screening COVID-19," "COVID-19 and 1918 influenza pandemic" and "colorectal cancer and Spanish flu." We also used these and other search terms, as needed, in Google searches. With Google searches, we focused on finding additional information from websites of organizations, government agencies, or other reputable sources including meeting abstracts. Below is a flowchart summarizing the methods for retrieving and selecting scientific articles from the PubMed database (Figure 1).

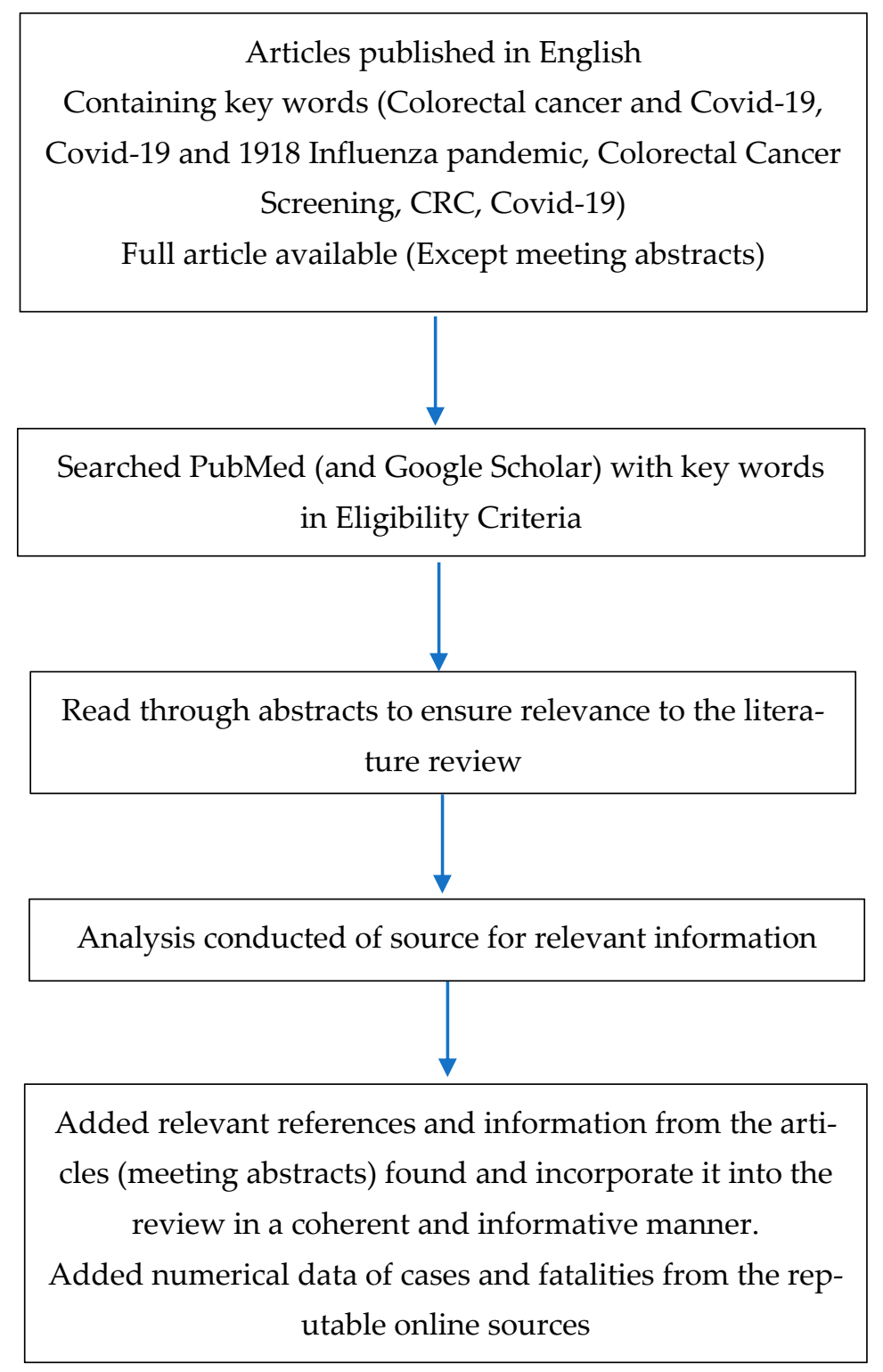

Figure 1. A flowchart describing eligibility criteria of relevant sources employed. 


\section{Immediate Delays in CRC Screening and Their Predicted Consequences}

In the early stages of COVID-19 pandemic, most healthcare systems around the world were not adequately prepared to handle what was about to come. CRC-screening tests were halted as national and regional lockdowns began, not to mention that healthcare centers needed to prioritize COVID-19 patients. Several studies have shown how much CRC-screenings decreased in the first few months of the pandemic. One study in the Netherlands compared the number of endoscopies conducted between 15 March 2020, and 25 June 2020, to the number of endoscopies conducted in the same period of 2019, using a database that gathers data from 20 hospitals in the Netherlands. It was found that there were only 9776 endoscopies performed in the 2020 period compared to 19,296 in the 2019 period. Also, colonoscopy procedures decreased by 55\% (from 12,219 to 5609) at the same time [26]. Similarly, a retrospective analysis on surveillance colonoscopy (in patients at high-risk for $\mathrm{CRC}$ ) in South Australia revealed that there was a $51.1 \%$ decrease in surveillance colonoscopy procedures from April-June 2019 compared to April-June 2020, the period where the region faced the most difficulty due to COVID-19 [27]. The USA experienced greater decreases in CRC screenings. In one study involving 20 medical centers, encompassing more than 28 million patients total, it was determined that there was a 38.4\% decrease in March 2020 compared to March 2019 and an 84.5\% decrease was observed in April 2020 compared to April 2019 [28]. Furthermore, another study (unpublished, presented at virtual UEG week 2021) of hospitals in Spain found that there was a 40.4\% decrease in CRC diagnosis from the pre-pandemic period (of March 2019 to March 2020) to the pandemic period (of March 2020 to February 2021). On top of this, the author of the study said that there were fewer tumors diagnosed during the pandemic period by screening and more by the presenting symptomology [29]. It was also reported that there was trend toward a higher presentation of stage 4 tumors in the pandemic period. This increase in stage 4 tumors suggests that delays in the ability to get screened within the pandemic period led to later stages of cancer being diagnosed in patients-a highly worrisome change. Overall, in many different countries, similar declines in CRC screening were observed.

There are multiple modeling studies published that have predicted the consequences of delayed CRC screening and diagnosis, and most of these predictions are rather alarming. For example, in a population-based modeling study done in the United Kingdom (UK), in which data of 24,975 CRC patients were analyzed, it was estimated that there would be an additional death toll of 1445 to 1563 people up to five years post-diagnosis due to delays in screening and consequent late diagnoses [30]. Similarly, a microsimulation modeling study was done in Canada estimating the clinical long-term impact of these delays and interruptions in CRC screening. The model projected that in terms of primary screening, a six-month suspension could result in an increase in CRC incidence by 2200 cases along with an excess of 960 deaths [31]. In the British Journal of Cancer, it was estimated using microsimulation models that without catching up to missed screenings, the death rate for colorectal cancer will increase to 2.5 per 100,000 people in the next decade [32]. Furthermore, another modeling study predicted between the year 2020-2023, there would be about 1,176,942 to 2,014,164 less CRC screening due to delays in screening in the U.S [33]. It was also predicted that the reduction in cancer screening will lead to 8346 to 12,894 fewer CRC diagnoses and 6113 to 9301 fewer early-stage CRC diagnoses during the same period [33]. This portrays the fatal consequence of late diagnosis as early detection of CRC increases the overall chance of patient survival. All-in-all, these models outline a common narrative of a predicted increase in CRC incidence and mortality rates due to interruptions and delayed screenings of CRC. These screenings are crucial in cancer prevention as they allow for removals of precancerous lesions, preventing the advancement of the lesion to early stages of cancer [32,33]. Without these early screening and detection methods, the consequences could be fatal.

During the 1918 flu pandemic, CRC screenings, as we know them today, were not even around. For example, it was not until 1947 that stool testing, specifically FOBT, was 
used to detect CRC [34]. Also, the first colonoscopy was performed in 1969-over 50 years after the 1918 influenza pandemic [16,17]. A more contemporary public health crisis where we can say more definitively that CRC screening was affected is the 2013-2016 Ebola virus outbreak in Western Africa. As there is no published literature on this specific topic, and CRC is less common in Western Africa compared to other parts of the world, we can infer that any lockdown imposed during this time caused any scheduled CRC screenings to be delayed $[35,36]$. Ultimately, there truly is no other situation quite like the COVID-19 pandemic that affected CRC screening so drastically. The fact that there has never been a similar situation that affected CRC screening like COVID-19 has, is why it has been relatively difficult for healthcare providers to make decisions about how best to proceed in these times. One can expect that in the aftermath of the COVID-19 pandemic, healthcare in general and screening systems for CRC will improve to deal with future disasters like the current pandemic.

\section{Resuming CRC Screening during COVID-19 and Beyond}

Given the massive delays in screening with traditional methods, some healthcare centers looked toward allowing more CRC screenings to take place after initial waves of COVID-19. One study involving four healthcare locations in the UK was conducted to determine the safety of performing CTCs during the downturn period (May to July 2020) after the UK's initial peak period of COVID-19. CTC is a faster procedure compared to colonoscopy and lends itself to social distancing, given that the process involves a computed tomography (CT) scan where no patient-staff physical contact is necessary. The study was done safely as no patients or staff involved in the CTCs were found to have COVID-19 after the test [37]. Additionally, CCE involves minimal physical contact between patients and staff; in fact, only one medical provider is needed to administer the test to a patient that can also be done remotely [38]. Note that throughout the pandemic, the use of telemedicine picked up to meet the needs of the healthcare system. This approach extends to CRC screening, where telehealth appointments regarding CRC screening have increased [39,40]. Telehealth visits are still ongoing, even as in-person CRC screenings in hospitals or other medical settings are starting to resume [41-43]. These appointments provide a platform for doctors to discuss available screening options with patients during these circumstances.

More importantly, the use of FIT is arguably the best alternative to, or prior to, colonoscopy procedure during the COVID-19 pandemic. FIT detects hidden blood in the stool, an early sign or warning of a silent cancerous lesion in the colon and/or rectum. To have maximum effectiveness, FIT must be done once a year. With the use of kits containing directions and materials, patients can simply do the test at home and then send it to their medical provider [15,44]. FIT can serve as a triage to colonoscopy or other screening tests. One study in the UK found that using FIT during the pandemic allowed for improved utilization of resources regarding colonoscopy; specifically, by using the FIT before colonoscopy, they found that the number of patients referred for a colonoscopy decreased by $28 \%$ while still maintaining the amount of CRC diagnosis [45]. This trend was found when they looked at the number of colonoscopies performed over the course of 26 March 2020 to 2 July 2020 compared to 1 October 2019 to 31 December 2019, where there was no statistically significant difference in the number of CRC diagnoses. By not having colonoscopies (when they are not strictly necessary), it saves time and money for providers and patients who would have had to undergo colonoscopy if they had not first received FIT [45]. To give some context, in the UK, it costs the National Health Service (NHS) approximately $£ 372$ for a colonoscopy, as compared to $£ 5$ for each FIT [46]. While in the U.S., a colonoscopy costs an average of $\$ 2750$ for a patient, and depending on the type of insurance they have, they could be paying varying amounts; or, with no insurance, patients would have to pay the full amount [47]. In 2017, NHS funded a study known as NICE FIT study. It was conducted in 50 hospitals in UK with 9822 subjects to assess effectiveness and the accuracy of the home-based stool testing kits (FIT) to reduce invasive screening 
procedures like colonoscopies and results have recently published [46,48]. According to the results, the sensitivity of FIT for CRC in high-risk patients was $97.7 \%$ and $92.2 \%$ at cut-off values of 2 and $10 \mu \mathrm{g}$ hemoglobin per g of stool sample. Similarly, it showed $94.3 \%$ and $86.6 \%$ sensitivity in low-risk patients at the same cut-off. These results confirm the effectiveness of FIT use in investigations for CRC screening.

Similarly, Issaka et al. used a developed simulation model to determine that during a period of fewer CRC screenings-i.e., the COVID-19 pandemic - an increase in FIT tests is associated with increased colorectal screenings and diagnoses. More specifically, they estimated that there would be an increase of about 2836 CRC diagnoses and 588,844 CRC screenings, totaling up to about $68.9 \%$ of CRC diagnoses being in the early stage of cancer [33]. If this period of delayed CRC was extended, it was estimated that the number of screenings and diagnoses would also go up [33]. Thus, while a FIT test does not provide all the benefits of a colonoscopy, it is a crucial tool in distanced CRC screening to close the gap during the COVID-19 pandemic. Not only is this type of test beneficial for maintaining the presence of screening, but it can also help to reduce racial and socioeconomic disparities in that it provides an at-home, lower-cost alternative to the traditional colonoscopy [33]. Although racial disparity is not the main focus of this review, it should be noted that this existing issue of disparity in cancer prevention in minority and ethnic populations, was clearly exposed during the COVID-19 pandemic. Carethers et al. have discussed the beneficial role of at-home tests during the pandemic in decreasing overall disparity in medically underserved populations [49]. These stool-based non-invasive tests should be further considered and implemented as part of regular CRC screening programs to prevent countless deaths. Beyond their immediate CRC benefit, they lead to changes done in the realm of public health and overall patient well-being.

While FIT can and likely should be used more given the COVID-19 pandemic to triage patients, it cannot replace colonoscopy procedure and its functional utility. Furthermore, challenges people face in receiving CRC screening pre-pandemic have been amplified even more during the pandemic. For instance, people who might have a harder time making themselves available to come get a colonoscopy, due to work obligations, for instance, are even more likely to not get a colonoscopy during the pandemic due to fear of contracting COVID-19. For example, one study found that nearly $20 \%$ of people in their CRC sample said that they would not be as likely to go do a screening test during the pandemic as compared to before the pandemic [50]. Also, the fact that stress levels in the general population have increased because of the pandemic could be another reason why people are less likely to come to a hospital/medical center for any kind of CRC screening [51]. Even beyond CRC, patients were still reluctant for any kind of healthcare appointment in general. This reluctance can be due to multiple factors mentioned before, such as stress, fear, or overall emotional unsettledness. In the same study, it was shown that a significant portion of the population, about $36.9 \%$, have been reported to miss at least one healthcare appointment during the pandemic [51]. Therefore, there is even more uncertainty around the impact of these missed appointments even beyond CRC. This can be seen with overall delayed diagnosis and missed diagnosis in other types of cancers as well, which again have an increased death rate associated with prolonged, late diagnosis of the disease.

As stated, and implied previously, there is no published literature detailing the effects of the 1918 flu pandemic on colorectal cancer incidence in the years following the $1918 \mathrm{flu}$ pandemic. One reason could be lack of advanced medical care and unavailability of screening methodology almost a century ago. Of course, somewhat of a parallel between the 1918 flu pandemic and COVID-19 is that people were afraid to interact with others (outside of their homes), including physicians, for fear of contracting disease at the beginning and peak of the pandemic. The fact that present-day medical technology itself collapsed during the initial stages of COVID-19 pandemic (meaning it could not be best-utilized given the limitations of the pandemic-social distancing, lockdowns, etc.) made it difficult to conduct routine screenings to obtain early cancer diagnoses. 
Table 3 below summarizes the main findings of the studies related to COVID-19 included in this review.

Table 3. Summary of Main Findings of Studies Relevant to Colorectal Cancer Screening and COVID-19 Pandemic.

\begin{tabular}{|c|c|c|c|}
\hline $\begin{array}{l}\text { Authors \& } \\
\text { Reference\# }\end{array}$ & Journal & $\begin{array}{c}\text { Year } \\
\text { Published }\end{array}$ & Main Findings \\
\hline Johnson BA et al. [6] & Am J Surg & 2020 & $\begin{array}{l}\text { A delay in surgeries for breast, lung, and colon cancer } \\
\text { during the COVID-19 pandemic could decrease the chance } \\
\text { of survival for patients. }\end{array}$ \\
\hline Lantinga MA et al. [26] & Endoscopy & 2021 & $\begin{array}{l}\text { Data from a database, encompassing } 15 \text { hospitals in the } \\
\text { Netherlands were analyzed. Comparing the } 15 \text { March } \\
\text { 2019-25 June } 2019 \text { period to the } 15 \text { March } 2020-25 \text { June } 2020 \\
\text { period, it was seen that gastroscopies decreased by } 57 \% \text { and } \\
\text { colonoscopies decreased by } 55 \% \text {. }\end{array}$ \\
\hline Wassie MM et al. [27] & JGH Open & 2021 & $\begin{array}{c}\text { A retrospective data analysis was performed to compare } \\
\text { colonoscopy data from April-June } 2019 \text { to April-June } 2020 \\
\text { in South Australia. Colonoscopies decreased by } 51.1 \% \text { in the } \\
\text { COVID-19 time period, and } 46.1 \% \text { of colonoscopies were } \\
\text { delayed by at least } 6 \text { months. }\end{array}$ \\
\hline London JW et al. [28] & $\begin{array}{l}\text { JCO Clin Cancer } \\
\text { Inform }\end{array}$ & 2020 & $\begin{array}{l}\text { Data from the TriNetX data network, encompassing } 20 \\
\text { medical centers and more than } 28 \text { million patients total, } \\
\text { were analyzed. Comparing March } 2019 \text { to March 2020, there } \\
\text { was a } 38.4 \% \text { decrease in CRC screenings. Comparing April } \\
2019 \text { to April 2020, there was an } 84.5 \% \text { decrease. }\end{array}$ \\
\hline Domper Arnal MJ [29] & $\begin{array}{l}\text { Presented at: UEG } \\
\text { Week; 3-5 October } \\
2021 \text { (virtual meeting) }\end{array}$ & 2021 & $\begin{array}{c}\text { An unpublished study of hospitals in Spain found there was } \\
\text { a 40.4\% decrease in CRC diagnoses in March 2020-February } \\
\text { 2021, as compared to March 2019-March 2020. }\end{array}$ \\
\hline
\end{tabular}

This UK population-based modelling study aimed to

Maringe C et al. [30] Lancet Oncol $\quad 2021$

estimate the effects of COVID-19-related delays of CRC screening. Data for 24,975 people with CRC was collected, and the estimation of additional death toll was 1445 to 1563 people up to five years post-diagnosis.

This study utilized microsimulation models for two types of cancers, including $\mathrm{CRC}$, to determine what effects

Yong JH et al. [31] J Med Screen

2021 COVID-19 could have on CRC in Canada. With a 6-month delay in regular screening, CRC incidence and death would increase by 2200 people and 960 people, respectively.

Microsimulation models were used to simulate screening restart strategies for different types of cancers. If delays

Kregting LM et al. [32] $\quad$ Br J Cancer 2021 (due to the pandemic) were not caught up with, the CRC death rate would increase by 2.5 per 100,000 people in the next 10 years.

A simulation model was used to predict CRC outcomes between 2020 and 2023 in the U.S., including delays associated with the COVID-19 pandemic. The model Issaka RB et al. [33] JAMA Netw Open 2021 showed that there would be 1,176,942 to 2,014,164 less CRC screenings and 8346 to 12,894 fewer CRC diagnoses. Also, an increase in FIT could cause increases in CRC screenings $(655,825)$ and diagnoses $(2715)$.

Evaluation of CTCs conducted from May to July 2020 at four English hospital trusts was performed. 224 patients were scanned; of these, 169 who were followed up with on the phone reported no COVID-19 symptoms within 14 days of the test. 
Table 3. Cont

\begin{tabular}{|c|c|c|c|}
\hline $\begin{array}{l}\text { Authors \& } \\
\text { Reference\# }\end{array}$ & Journal & $\begin{array}{c}\text { Year } \\
\text { Published }\end{array}$ & Main Findings \\
\hline MacLeod C et al. [38] & Colorectal Dis & 2020 & $\begin{array}{l}\text { Colon capsule endoscopy is a screening method that can be } \\
\text { carried out safely during the COVID-19 pandemic and can } \\
\text { be used to triage for colonoscopy. }\end{array}$ \\
\hline Wahezi SE et al. [39] & $\begin{array}{l}\text { Best Pract Res Clin } \\
\text { Anaesthesiol }\end{array}$ & 2021 & $\begin{array}{l}\text { Telemedicine has greatly increased due to the COVID-19 } \\
\text { pandemic and will continue to be practiced post-pandemic. } \\
\text { More research on telemedicine is needed to better compare } \\
\text { it to in-person visits. }\end{array}$ \\
\hline $\begin{array}{c}\text { Kadakuntla A et al. } \\
\text { [40] }\end{array}$ & $\begin{array}{l}\text { World J Gastrointest } \\
\text { Oncol }\end{array}$ & 2021 & $\begin{array}{l}\text { The delays in CRC screening during COVID-19 can be } \\
\text { overcome by doing more stool-based tests, adjusting } \\
\text { screening protocols, and implementing more telehealth. } \\
\text { Telehealth has advantages including convenience and } \\
\text { improving patient compliance. }\end{array}$ \\
\hline Maclean W et al. [45] & Colorectal Dis & 2020 & $\begin{array}{c}\text { An observational cohort study in the UK was conducted to } \\
\text { evaluate how FIT could affect utilization of resources and } \\
\text { triage to colonoscopy. They found using FIT decreased } \\
\text { further progression to colonoscopy from } 62 \% \\
\text { (pre-pandemic) to } 34 \% \text {, while no significant change in the } \\
\text { diagnosis rate. }\end{array}$ \\
\hline D'Souza N et al. [48] & Br J Surg & 2021 & $\begin{array}{l}\text { From October } 2017 \text { to December } 2019 \text {, a study of } 50 \\
\text { hospitals in England including } 9822 \text { subjects showed that } \\
\text { the sensitivity of fecal immunochemical tests for CRC was } \\
97.7 \% \text { and } 92.2 \% \text { at cut-off values of } 2 \text { and } 10 \mu \mathrm{g} \\
\text { hemoglobin per g of stool sample. }\end{array}$ \\
\hline Carethers JM et al. [49] & $\begin{array}{c}\text { Cancer Prev Res } \\
\text { (Phila) }\end{array}$ & 2020 & $\begin{array}{l}\text { Minority populations in the United States face additional } \\
\text { challenges in receiving CRC screening (e.g., finances, } \\
\text { transportation, etc.). Thus, the delays in CRC screening } \\
\text { during the pandemic will increase their CRC risk. }\end{array}$ \\
\hline Wilson R et al. [50] & Prev Med & 2021 & $\begin{array}{l}\text { A cross-sectional online survey was conducted in the UK of } \\
\text { over } 7543 \text { adults between August and September 2020, and } \\
\text { follow-up interviews were conducted for } 30 \text { people. About } \\
20 \% \text { of participants indicated they would be less likely to go } \\
\text { to a CRC screening test during the pandemic. }\end{array}$ \\
\hline Mason MC et al. [51] & Cureus & 2021 & $\begin{array}{l}\text { A cross-sectional study, done from January-April 2021, was } \\
\text { performed (totaling } 103 \text { participants). Over } 30 \% \text { participants } \\
\text { missed a routine colonoscopy during the pandemic. }\end{array}$ \\
\hline
\end{tabular}

\section{Conclusions}

There is no denying that the effects of COVID-19 on cancer screening are extreme. With interruptions and delays in screening tests, CRC mortality rates have been predicted to increase. Although the outlook of CRC seems ominous, one can take away countless lessons from the COVID-19 pandemic in terms of screening, diagnosis, and overall prevention of CRC. One key component to consider for the future of CRC screening and diagnosis is more utilization of alternative approaches, such as FIT tests. This remote option gives patients a lot of flexibility with their screening, as they are able to take the test safely in the comfort of their own home. It can also potentially provide a better allocation of resources, in terms of the fact that it can help prioritize patients who need colonoscopy over others due to the relative severity of their disease stage. Along with that, the accessibility of FIT tests can improve racial health disparities. Even as regular screening practices start to pick back up again as COVID-19 vaccines are being administered in many developed countries, the pandemic has still altered the framework through which healthcare providers view CRC screening. A lot has been learned and there are many key takeaways. One of these takeaways is that while colonoscopy will always be the gold standard in terms of CRC 
screening, FIT tests and other screening methods have significant strengths and unique attributes that make them utilizable and optimal in different situations.

Prediction models were utilized to have a sense of the extent to which delayed screenings could impact the population. In past pandemics, such as the 1918 flu pandemic, there were no clear data to demonstrate if the same trends occurred in terms of increased deaths due to missed screenings, and delayed diagnoses of CRC. The same could be said about the Ebola virus outbreak, a more contemporary epidemic, because there is no literature about these exact trends either. It is extremely important that we must use what we know about how COVID-19 affected CRC to prepare for and prevent human suffering in future pandemics and other public health crises. Doing so could help prevent the effects on CRC of a future event from being as catastrophic as early diagnosis, along with proper intervention, saves lives. More recently, as COVID-19 vaccines become more and more available, regular screening practices have started to pick back up again. However, the consequent delays previously mentioned still take a toll on human lives in terms of delayed diagnosis and advancement of CRC. One can hope that lessons learned from the current pandemic will make us efficient enough to respond by strategizing existing resources and rationalizing health systems to optimize cancer screening and cancer therapies by making smart decisions to protect human lives if we must go through this crisis again.

This manuscript provides a perspective for the medical community regarding the continuation of screening programs for chronic and fatal diseases (i.e., different cancers including $\mathrm{CRC}$ ) even during the pandemic times that can lead to a decrease in mortality for these conditions that otherwise was increased due to diagnosis in the late stage of these diseases. There are some strengths and limitations to this review. The main point is that this manuscript compares CRC screening during the COVID-19 pandemic to CRC screening in the 1918 flu pandemic and the Ebola virus outbreak, which has never been done previously in other reviews. Also, this review compiles qualitative information pertaining to several countries, giving it a more global perspective. One of the main limitations to this review is that the data for CRC screening during and in the years following the 1918 flu pandemic is very limited (mainly due to the fact that screening was not prevalent at that time). Also, the COVID-19 pandemic is still ongoing, so many of the statistics, as well as model predictions, are limited to the point in time of the pandemic at which they were gathered and conducted.

The consequence of delayed and missed CRC diagnoses will, unfortunately, be felt for years to come by everyone in the world. There is still a lot left to learn and discover in terms of CRC screening, and the challenges that have had to be overcome in the present pandemic show that there certainly is more capacity to improve CRC screening. Unfortunately, there have been fatal implications due to COVID-19. However, by reflecting on and analyzing all of what COVID-19 affected in terms of CRC screening (and all other areas), the healthcare population/industry, researchers, etc., can form plans and solutions to help prevent these events from reoccurring.

Author Contributions: I.H. and D.Z. contributed equally to this project. M.N.A. is the corresponding author. The specific contributions of authors are as follows; Conceptualization, M.N.A.; methodology, I.H., D.Z. and M.N.A.; software, I.H., D.Z. and M.N.A.; validation, I.H., D.Z. and M.N.A.; formal analysis, I.H., D.Z. and M.N.A.; investigation, I.H., D.Z. and M.N.A.; resources, I.H., D.Z. and M.N.A.; data curation, I.H., D.Z. and M.N.A.; writing—original draft preparation, I.H., D.Z. and M.N.A.; writing-review and editing, I.H., D.Z. and M.N.A.; visualization, M.N.A.; supervision, M.N.A.; project administration, M.N.A.; funding acquisition, M.N.A. All authors have read and agreed to the published version of the manuscript.

Funding: This study was funded by an MCubed (University of Michigan) grant (to MNA) and funding from the American Society for Investigative Pathology (ASIP) Summer Research Opportunity Program in Pathology (SROPP) to (MNA).

Institutional Review Board Statement: Not applicable.

Informed Consent Statement: Not applicable. 
Data Availability Statement: The data used in this paper come from sources found via searches on PubMed or Google (Google Scholar). See the References section for each source used.

Conflicts of Interest: The authors declare no conflict of interest.

\section{References}

1. Belser, J.A.; Tumpey, T.M. The 1918 flu, 100 years later. Science 2018, 359, 255. [CrossRef] [PubMed]

2. 1918 Pandemic (H1N1 Virus). Centers for Disease Control and Prevention Website. Available online: https://www.cdc.gov/flu/ pandemic-resources /1918-pandemic-h1n1.html (accessed on 26 October 2021).

3. Myrskylä, M.; Mehta, N.K.; Chang, V.W. Early life exposure to the 1918 influenza pandemic and old-age mortality by cause of death. Am. J. Public Health 2013, 103, e83-e90. [CrossRef]

4. Overview of Testing for SARS-CoV-2 (COVID-19). cdc.gov. Updated 17 March 2021. Available online: https://www.cdc.gov/ coronavirus/2019-ncov/hcp/testing-overview.html\#Introduction (accessed on 25 October 2021).

5. COVID-19 Dashboard by the Center for Systems Science and Engineering (CSSE) at Johns Hopkins University (JHU). coronavirus.jhu.edu. Available online: https:/ / coronavirus.jhu.edu/map.html (accessed on 21 November 2021).

6. Johnson, B.A.; Waddimba, A.C.; Ogola, G.O.; Fleshman, J.W., Jr.; Preskitt, J.T. A systematic review and meta-analysis of surgery delays and survival in breast, lung and colon cancers: Implication for surgical triage during the COVID-19 pandemic. Am. J. Surg. 2020, 222, 311-318. [CrossRef]

7. DeGroff, A.; Miller, J.; Sharma, K.; Sun, J.; Helsel, W.; Kammerer, W.; Rockwell, T.; Sheu, A.; Melillo, S.; Uhd, J.; et al. COVID-19 impact on screening test volume through the National Breast and Cervical Cancer early detection program, January-June 2020, in the United States. Prev. Med. 2021, 151, 106559. [CrossRef] [PubMed]

8. Santoro, G.A.; Grossi, U.; Murad-Regadas, S.; Nunoo-Mensah, J.W.; Mellgren, A.; Di Tanna, G.L.; Gallo, G.; Tsang, C.; Wexner, S.D.; DECOR-19 Collaborative Group. DElayed COloRectal cancer care during COVID-19 Pandemic (DECOR-19): Global perspective from an international survey. Surgery 2021, 169, 796-807. [CrossRef] [PubMed]

9. American Cancer Society. Key Statistics for Colorectal Cancer. Updated 12 January 2021. Available online: https://www.cancer. org/cancer/colon-rectal-cancer/about/key-statistics.html (accessed on 26 October 2021).

10. Mitrut, P.; Docea, A.O.; Kamal, A.M.; Mitrut, R.; Calina, D.; Gofita, E.; Padureanu, V.; Gruia, C.; Streba, L. Colorectal Cancer and Inflammatory Bowel Disease. IntechOpen 2016, 186-199. [CrossRef]

11. Zlatian, O.M.; Comănescu, M.V.; Roşu, A.F.; Roşu, L.; Cruce, M.; Găman, A.E.; Călina, C.D.; Sfredel, V. Histochemical and immunohistochemical evidence of tumor heterogeneity in colorectal cancer. Rom. J. Morphol. Embryol. 2015, 56, 175-181. [PubMed]

12. Sehnalova, I.; Rihova, B.; Nemecek, R.; Kintrova, K.; Demlova, R. The Real-World Cost and Effectiveness Study of Treating mCRC with Bevacizumab Followed by Cetuximab or Panitumumab in WT Kras Patients. Farmacia 2020, 68, 572-578. [CrossRef]

13. Aslam, M.N.; McClintock, S.D.; Jawad-Makki, M.A.H.; Knuver, K.; Ahmad, H.M.; Basrur, V.; Bergin, I.L.; Zick, S.M.; Sen, A.; Turgeon, D.K.; et al. A Multi-Mineral Intervention to Modulate Colonic Mucosal Protein Profile: Results from a 90-Day Trial in Human Subjects. Nutrients 2021, 13, 939. [CrossRef]

14. McClintock, S.D.; Colacino, J.A.; Attili, D.; Dame, M.K.; Richter, A.; Reddy, A.R.; Basrur, V.; Rizvi, A.H.; Turgeon, D.K.; Varani, J.; et al. Calcium-Induced Differentiation of Human Colon Adenomas in Colonoid Culture: Calcium Alone versus Calcium with Additional Trace Elements. Cancer Prev. Res. 2018, 11, 413-428. [CrossRef] [PubMed]

15. American Cancer Society Medical. Colorectal Cancer Screening Tests. Updated 29 June 2020. Available online: https:/ www. cancer.org/cancer / colon-rectal-cancer/detection-diagnosis-staging/screening-tests-used.html (accessed on 26 October 2021).

16. Wolff, W.I. Colonoscopy: History and development. Am. J. Gastroenterol. 1989, 84, 1017-1025. [PubMed]

17. Wolff, W.I.; Shinya, H. Earlier diagnosis of cancer of the colon through colonic endoscopy (colonoscopy). Cancer 1974, 34, 912-931. [CrossRef]

18. Ramai, D.; Zakhia, K.; Etienne, D.; Reddy, M. Philipp Bozzini (1773-1809): The earliest description of endoscopy. J. Med. Biogr. 2018, 26, 137-141. [CrossRef]

19. Zuber, T.J. Flexible sigmoidoscopy. Am. Fam. Physician 2001, 63, 1375-1388.

20. Rodney, W.M.; Felmar, E. Why Flexible Sigmoidoscopy Instead of Rigid Sigmoidoscopy? J. Fam. Pract. 1984, $19,471-476$. [PubMed]

21. De Franchis, R.; Rondonotti, E.; Villa, F. Capsule endoscopy-State of the art. Dig. Dis. 2007, 25, 249-251. [CrossRef]

22. Cave, D.R. Technology Insight: Current status of video capsule endoscopy. Nat. Clin. Pract. Gastroenterol. Hepatol. 2006, 3, 158-164. [CrossRef]

23. Wingo, P.A.; Cardinez, C.J.; Landis, S.H.; Greenlee, R.T.; Ries, L.A.G.; Anderson, R.N.; Thun, M.J. Long-term trends in cancer mortality in the United States, 1930-1998. Cancer 2003, 97, 3133-3275. [CrossRef] [PubMed]

24. Siegel, R.; Desantis, C.; Jemal, A. Colorectal cancer statistics, 2014. CA Cancer J. Clin. 2014, 64, 104-117. [CrossRef]

25. Siegel, R.L.; Fedewa, S.A.; Anderson, W.F.; Miller, K.D.; Ma, J.; Rosenberg, P.S.; Jemal, A. Colorectal Cancer Incidence Patterns in the United States, 1974-2013. J. Natl. Cancer Inst. 2017, 109, djw322. [CrossRef]

26. Lantinga, M.A.; Theunissen, F.; Ter Borg, P.C.J.; Bruno, M.J.; Ouwendijk, R.J.T.; Siersema, P.D.; On behalf of the Trans.IT Foundation Study Group. Impact of the COVID-19 pandemic on gastrointestinal endoscopy in the Netherlands: Analysis of a prospective endoscopy database. Endoscopy 2021, 53, 166-170. [CrossRef] 
27. Wassie, M.M.; Agaciak, M.; Cock, C.; Bampton, P.; Young, G.P.; Symonds, E.L. The impact of coronavirus disease 2019 on surveillance colonoscopies in South Australia. JGH Open 2021, 5, 486-492. [CrossRef]

28. London, J.W.; Fazio-Eynullayeva, E.; Palchuk, M.B.; Sankey, P.; McNair, C. Effects of the COVID-19 Pandemic on Cancer-Related Patient Encounters. JCO Clin. Cancer Inform. 2020, 4, 657-665. [CrossRef] [PubMed]

29. Altersitz, K. Colorectal Cancer Diagnoses Dropped by $40 \%$ during Pandemic. Published 4 October 2021. (Source: Domper Arnal MJ. P1086. Presented at a Virtual Meeting: United European Gastroenterology (UEG) Week; 3-5 October 2021). Available online: https: / / www.healio.com/news/gastroenterology/20211004/colorectal-cancer-diagnoses-dropped-by-40-during-pandemic? utm_source=selligent\&utm_medium=email\&utm_campaign=news\&M_BT=3261842388539 (accessed on 14 October 2021).

30. Maringe, C.; Spicer, J.; Morris, M.; Purushotham, A.; Nolte, E.; Sullivan, R.; Rachet, B.; Aggarwal, A. The impact of the COVID-19 pandemic on cancer deaths due to delays in diagnosis in England, UK: A national, population-based, modelling study. Lancet Oncol. 2020, 21, 1023-1034. [CrossRef]

31. Yong, J.H.; Mainprize, J.G.; Yaffe, M.J.; Ruan, Y.; Poirier, A.E.; Coldman, A.; Nadeau, C.; Iragorri, N.; Hilsden, R.J.; Brenner, D.R. The impact of episodic screening interruption: COVID-19 and population-based cancer screening in Canada. J. Med. Screen. 2021, 28, 100-107. [CrossRef]

32. Kregting, L.M.; Kaljouw, S.; de Jonge, L.; Jansen, E.E.L.; Peterse, E.F.P.; Heijnsdijk, E.A.M.; van Ravesteyn, N.T.; Lansdorp-Vogelaar, I.; de Kok, I.M.C.M. Effects of cancer screening restart strategies after COVID-19 disruption. Br. J. Cancer 2021, 124, 1516-1523. [CrossRef]

33. Issaka, R.B.; Taylor, P.; Baxi, A.; Inadomi, J.M.; Ramsey, S.D.; Roth, J. Model-Based Estimation of Colorectal Cancer Screening and Outcomes During the COVID-19 Pandemic. JAMA Netw. Open 2021, 4, e216454. [CrossRef]

34. Hajdu, S.I.; Vadmal, M. A note from history: Landmarks in history of cancer, Part 6. Cancer 2013, 119, 4058-4082. [CrossRef] [PubMed]

35. Irabor, D.O. Emergence of Colorectal Cancer in West Africa: Accepting the Inevitable. S. Afr. Gastroenterol. Rev. 2017, 15, 11-16. [CrossRef]

36. Ebola Crisis: Sierra Leone Lockdown to Hit 2.5 m People. Published 19 March 2015. Available online: https:/ /www.bbc.com/ news / world-africa-31966989 (accessed on 9 September 2021).

37. Peprah, D.; Plumb, A.; Corr, A.; Muckian, J.; Smith, K.; Sergot, A.; Kuah, J.Y.; Stephenson, J. Re-initiation of CT colonography services during the COVID-19 pandemic: Preliminary evaluation of safety. Br. J. Radiol. 2021, 94, 20201316. [CrossRef] [PubMed]

38. MacLeod, C.; Wilson, P.; Watson, A.J.M. Colon capsule endoscopy: An innovative method for detecting colorectal pathology dur-ing the COVID-19 pandemic? Colorectal Dis. 2020, 22, 621-624. [CrossRef]

39. Wahezi, S.E.; Kohan, L.R.; Spektor, B.; Brancolini, S.; Emerick, T.; Fronterhouse, J.M.; Luedi, M.M.; Colon, M.A.; Kitei, P.M.; Anitescu, M.; et al. Telemedicine and current clinical practice trends in the COVID-19 pandemic. Best Pract. Res. Clin. Anaesthesiol. 2021, 35, 307-319. [CrossRef]

40. Kadakuntla, A.; Wang, T.; Medgyesy, K.; Rrapi, E.; Litynski, J.; Adynski, G.; Tadros, M. Colorectal cancer screening in the COVID-19 era. World J. Gastrointest. Oncol. 2021, 13, 238-251. [CrossRef]

41. American Cancer Society. Cancer Screening During the COVID-19 Pandemic. Updated 23 April 2021. Available online: https:// www.cancer.org/healthy / find-cancer-early/cancer-screening-during-covid-19-pandemic.html (accessed on 28 September 2021).

42. Bowel Cancer Screening. Updated April 2021. Available online: https://www.bowelcanceruk.org.uk/about-bowel-cancer/ screening/ (accessed on 28 September 2021).

43. Epic Health Research Network. Delayed Cancer Screenings. Available online: https://ehrn.org/articles/delays-in-preventivecancer-screenings-during-covid-19-pandemic/ (accessed on 28 September 2021).

44. Myint, A.; Roh, L.; Yang, L.; Connolly, L.; Esrailian, E.; May, F.P. Noninvasive Colorectal Cancer Screening Tests Help Close Screening Gaps During Coronavirus Disease 2019 Pandemic. Gastroenterology 2021, 161, 712-714.e1. [CrossRef]

45. Maclean, W.; Limb, C.; Mackenzie, P.; Whyte, M.B.; Benton, S.C.; Rockall, T.; Jourdan, I. Adoption of faecal immunochemical testing for 2-week-wait colorectal patients during the COVID-19 pandemic: An observational cohort study reporting a new service at a regional centre. Colorectal Dis. 2020, 23, 1622-1629. [CrossRef] [PubMed]

46. New NHS Study Expected to almost Halve Number of Endoscopies by 2020. Published 29 September 2017. Available online: https: / www.bowelcanceruk.org.uk/news-and-blogs/news/nhs-study-finds-new-screening-test-could-almost-halveendoscopy-procedures-by-2020/ (accessed on 14 October 2021).

47. Vanvuren, C. How Much Does a Colonoscopy Cost? Available online: https://www.newchoicehealth.com/colonoscopy/cost (accessed on 14 October 2021).

48. D'Souza, N.; Delisle, T.G.; Chen, M.; Benton, S.C.; Abulafi, M.; NICE FIT Steering Committee. Faecal immunochemical testing in symptomatic patients to prioritize investigation: Diagnostic accuracy from NICE FIT Study. Br. J. Surg. 2021, 108, 804-810. [CrossRef] [PubMed]

49. Carethers, J.M.; Sengupta, R.; Blakey, R.; Ribas, A.; D'Souza, G. Disparities in Cancer Prevention in the COVID-19 Era. Cancer Prev. Res. 2020, 13, 893-896. [CrossRef] [PubMed]

50. Wilson, R.; Quinn-Scoggins, H.; Moriarty, Y.; Hughes, J.; Goddard, M.; Cannings-John, R.; Whitelock, V.; Whitaker, K.L.; Grozeva, D.; Townson, J.; et al. Intentions to participate in cervical and colorectal cancer screening during the COVID-19 pandemic: A mixed-methods study. Prev. Med. 2021, 153, 106826. [CrossRef]

51. Mason, M.C.; Vedhanayagam, K.; Jernigan, J.A. Evaluating Patient Adherence to Routine and Symptom Indicated Colonoscopies during the COVID-19 Pandemic. Cureus 2021, 13, e16711. [CrossRef] [PubMed] 